\title{
Socialización, medios de comunicación y ética
}

Socialization, media and ethics

\author{
Zoila Marlubeth Guzmán Hurtado* \\ Escuela Profesional de Ciencias de la Comunicación, \\ Universidad de San Martín de Porres, Perú
}

\section{Resumen}

En toda sociedad, cada uno de sus componentes y cada una de sus instituciones cumplen un rol determinante. El rol de los medios de comunicación es vital para sustentar la socialización, habiendo llegado incluso a ser llamados elementos democratizadores. Pero hoy en día están operando en contra de sus reales funciones y asumiendo a todas luces comportamientos antiéticos.

Esto no solamente se pone de manifiesto en el periodismo cada vez más desprestigiado, también está operando en los distintos formatos y géneros de manera cada vez más acentuada. Los programas de entretenimiento incurren con frecuencia en la vulgaridad y con toda impunidad pisotean la Ley $N^{\circ} 28278$ (Ley de Radio y Televisión), de tal manera que han llegado a generar la intervención del Poder Judicial, evidenciando que los medios de comunicación y los comunicadores no se pueden autorregular.

Pero ¿por qué hemos llegado a esta crisis? ¿Qué pasó con los comunicadores, con los profesionales de la verdad? Es entonces cuando caemos en cuenta de que el comunicador, en sus distintas ramas, debe recuperar su identidad como profesional y no limitarse a ser solamente un buscador de likes o de rating.

Este es un artículo Open Access bajo la licencia Creative Commons Atribución-NoComercial-Compartirlgual 4.0

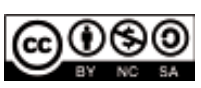


Palabras clave: medios de comunicación, socialización, entretenimiento, identidad, ética.

\begin{abstract}
In every society, each of its components and each of its institutions plays a determining role. The role of the media is vital to sustain socialization, having even come to be called democratizing elements. But today they are operating against their real functions and clearly engaging in unethical behavior.

This is not only evident in journalism that is increasingly discredited, it is also operating in different formats and genres in an increasingly accentuated way. Entertainment programs frequently incur vulgarity and with impunity trample Law $\mathrm{N}^{\circ} 28278$ (Radio and Television Law), in such a way that they have come to generate the intervention of the Judicial Power, evidencing that the media and the communicators cannot self-regulate.

But why have we reached this crisis? What happened to the communicators, to the professionals of the truth? It is then when we realize that the communicator, in his different branches, must recover his identity as a professional and not limit himself to being only a search engine for «likes» or ratings.
\end{abstract}

Keywords: media, socialization, journalism, entertainment, ethics.

\title{
Introducción
}

Cada una de las empresas o instituciones en la sociedad cumplen distintas funciones que se acoplan igual que un engranaje y hacen que todo el aparato social funcione, pero vemos con total permisibilidad cómo va perdiendo sentido todo aquello que llevó al progreso de la humanidad. El relativismo, el pragmatismo y su cuantificación solamente se ocupan de medir el crecimiento, mas no el desarrollo, y hemos aprendido a convivir de manera indiferente con la guerra, el hambre, la delincuencia, el crimen organizado, la vulgaridad, etc.; es decir, todo lo que contribuye a destruir el espíritu. Se abandona paulatinamente la práctica de una sana convivencia 
y en cambio, con mucho entusiasmo, se dejan de lado los valores humanos y todo aquello que nos aleja de los animales salvajes.

Año tras año nos quejamos de la misma problemática, descrita magistralmente por Arboccó y O'Brien (2012): el ser humano pasivo, que asume lo que el mercado le proporciona y se transforma en un consumidor. Coinciden en ello con lo expresado por Roberto Pettinato, comunicador y periodista argentino: «La televisión basura es la forma cretina que tiene el medio de crear programas mediocres que miden tu incultura y tu desgracia para igualarla, y jamás potenciar lo bueno de esta vida». Palabras duras, pero reales, que hablan de un sector empresarial salvaje que busca la mercantilización en contra de los derechos de los consumidores de mass media.

El concepto de «televisión basura» se remonta a la última década del siglo pasado. En los noventa, con este término, se hizo referencia a una manera de producción audiovisual que se caracterizó por la explotación de una tendencia que enaltece lo sórdido, lo malsano y lo escandaloso como mecanismos para agradar a la teleaudiencia. La «televisión basura» queda definida como tal por los temas que aborda y por la distorsión a la que recurre para tratar dichos temas a través de la exhibición de personajes impresentables.

Hoy en día, lamentablemente, la ética en la producción de contenidos televisivos es un saludo a la bandera. Y no podría ser de otro modo, puesto que las televisoras se encuentran bajo la administración de negociantes que no responden a ningún código de ética ni de responsabilidad social y, como consecuencia de ello, atropellan la ley de radio y televisión ya referida, y tienen el lucro como único fin. Esta situación presenta un grado de «complicidad» con las autoridades, entre otros actores. La sociedad ha permitido que, por lo general, lo que se transmite por televisión sea consentido, creído; y aunque se quisiera retomar algún punto de vista distinto, lamentablemente se colisionará con la unidireccionalidad de este medio.

El papel que desarrolla la comunicación en la sociedad es fundamental porque con sus mensajes, información, datos y demás nos marca la pauta del ¿hacia dónde vamos? Esta es la pregunta que honestamente debemos responder si queremos salvar a la humanidad. 


\section{Socialización}

Se trata del factor de desarrollo indispensable para que el ser humano no pierda su valor, a decir de grandes clásicos como Durkheim (2011 [1883]) y Vygotsky (1981). Por su parte, Piaget defiende a la educación como componente indispensable de socialización y, desde el análisis comunicacional, socializar es esencial para la evolución del hombre en grupo. A decir de Mac Bride (1980), las empresas de comunicación y sus profesionales tienen el deber de cimentar una base de saberes e ideales que promuevan la integración y sentido de pertenencia entre los individuos para que puedan interactuar a favor del bienestar común.

Somos espectadores pasivos del quiebre más grave de la socialización en la historia de la civilización, nos conformamos con los enunciados de ciertos grupos que se presentan con el falso estandarte de la reivindicación de derechos $\mathrm{y}$, sin embargo, exhiben una millonaria propaganda que asolapa la polarización de la sociedad. Crean polémica y división con falsas promesas endulzadas en el individualismo nocivo, cuando la única solución es velar por el cumplimiento de lo establecido en sus respectivas cartas magnas, promoviendo la educación y los valores para tener mejores generaciones que propaguen el desarrollo, mirando a este planeta como nuestra única casa, a la cual a estas alturas de la existencia humana ya deberíamos llamar hogar.

Algunos de esos grupos radicales reclaman tolerancia y son los más intolerantes, desean que se les reconozca derechos y se los niegan a los demás; en consecuencia, la comunicación ha perdido su sentido y la palabra solamente tiene valor para quien la enuncia.

\section{Medios de comunicación: ¿qué papel juegan realmente frente a su rol de socialización?}

Numerosos estudios en todo el planeta denuncian la ausencia de Responsabilidad Social Corporativa (RSC), sobre todo en los soportes audiovisuales (desde los años veinte del siglo pasado). Han surgido teorías que nos llevan a considerar una legislación prudente que, sin llegar a la censura, garantice los derechos de los ciudadanos y usuarios de las tecnologías de la información y la comunicación (TIC). 


\section{CASOS DIGNOS DE OBSERVACIÓN Y SANCIÓN}

\section{Caso «Checho» Ibarra / Bloque deportivo dentro de informativo}

\section{Ficha técnica}

Medio de comunicación: Latina Televisión Canal 2.

Propietario: Grupo Enfoca.

Operado por Compañía Latinoamericana de Radiodifusión

Jesús Zamora (presidente del directorio)

Juan Pablo Olivares (gerente general

Luis Guillermo Camacho (gerente de contenidos)

Señal en Lima: OAY-4Y (analógica), 1856 (TDT)

Programa: 90 Matinal (5:00 - 9:00 a.m.)

Secuencia: Deporte

Conductor: Sergio «Checho» Ibarra

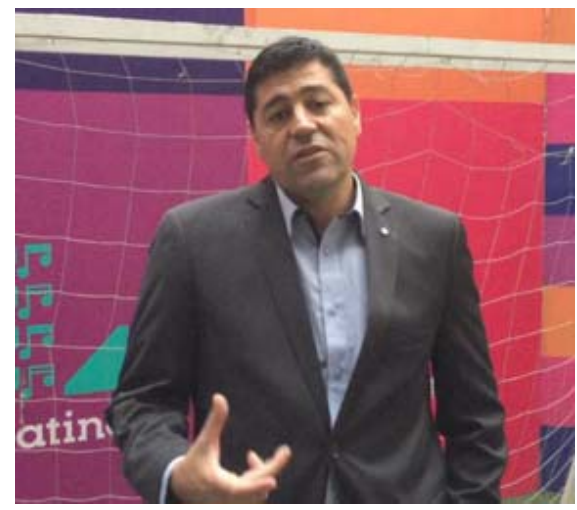

Fuente: https://www.latina.pe/

Fecha de emisión: Viernes 10 de septiembre de 2021, después del partido Perú - Brasil por las Eliminatorias Qatar 2022.

Descripción del contenido: En esta sección del noticiero, que figura como deportiva, el conductor solamente aclara fechas, critica sin ningún sentido técnico los partidos jugados (pese a haber sido un destacado futbolista local) y convierte al segmento en un reality, ya que hace gala de su peculiar forma de vestir, peinado, arengas, etc.; realiza comentarios inapropiados con sus pares que leen las noticias; y se exhibe prácticamente como un payaso que tiene que bailar y hacer piruetas para arrancar sonrisas.

Rumbo a Qatar 2022: En la fecha mencionada, Sergio Ibarra generó un discurso sobre la incierta situación de la selección peruana rumbo a Qatar y la única solución que esgrimió fue que la selección de Bolivia tenía que perder ante la de Argentina, y que Chile debía hacer lo propio ante Colombia.

En ningún momento responsabilizó a la selección por su deficiente desempeño en las eliminatorias, no habló de la técnica, ni de la performance de los deportistas. No analizó técnicamente al rival, solamente reiteró una propuesta mediocre y mezquina, que configuró una situación inmoral, pero 
que fue muy bien recibida por los fanáticos del fútbol. Un conductor o un locutor es un comunicador cuyo deber es motivar a sus audiencias a conseguir sus metas a corto o a largo plazo, a buscar la manera de lograr los objetivos colectivos socializando correctamente.

Análisis: El mundo es testigo de la crisis más grave que atraviesa el periodismo por la ola de fake news o por la «infodemia», que termina siendo la ausencia del trabajo periodístico al romperse todos los cánones de la ética profesional, como una avalancha que borra del mapa un pacífico paisaje. Lo más delicado de esta problemática es que algunas personas ejercen la noble labor del periodismo sin ningún respeto por el público ni por la profesión, no se preparan para la conducción o presentación, tampoco para las entrevistas y hacen preguntas inútiles que desdibujan la realidad. No investigan con rigor, desvían la atención del público y hacen un reality show, convirtiéndose en los protagonistas de la noticia. Otros se limitan a pasar videos de YouTube o de cámaras de seguridad. También están los que preguntan solo por opiniones: «Ministro, ¿cómo se siente...?», «Alcalde, ¿qué piensa de lo que dijo el congresista tal...?».

A toda esta vorágine de desinformación hay que agregar lo que hace más de cuarenta años denunció un informe de la UNESCO: la autocensura; es decir, el callar por voluntad propia para no perder los favores políticos o económicos de los grupos de poder. Lastimosamente, estas actitudes se vuelven cada vez más visibles para el público en general, lo que ha generado una aversión casi generalizada hacia los hombres de prensa, quienes en ocasiones son blanco de ofensas, repudio y golpes en las calles donde cubren un hecho noticioso.

En el caso de Sergio Ibarra vemos dos falencias de grandes dimensiones. La primera: él trabaja en un programa informativo, pero no cumple los mínimos estándares para poder hacerlo. Se entiende por informar el proceso minucioso que realizan los profesionales competentes para convertir los hechos de la vida real en noticias, con el rigor y el cuidado ético necesarios para que los ciudadanos puedan tomar conciencia de su realidad y mejorarla.

Es importante rescatar que solamente se hace periodismo cuando se logra que el televidente, lector o radioescucha, en cualquiera de las plataformas 
comunicativas, tome una decisión adecuada sobre su realidad para generar el cambio social. De lo contrario, la función informativa no se cumple porque continúa el estado de caos, violencia, delincuencia, mediocridad, criminalidad, desastre, etc. Por lo tanto, no informa quien no logra dotar de los insumos necesarios a sus audiencias para desarrollar la capacidad de intervención en su entorno, procurando calidad de vida. Ya hemos dicho que el periodista o comunicador debe motivar a la población a alcanzar sus metas colectivas e individuales, comprendiendo y respetando las aspiraciones de todos (MacBride, 1980). El conductor Ibarra, muy lejos de una actitud periodística, optó por una posición mezquina y mediocre el 10 de septiembre del 2021, nombrando a los equipos que debían perder para que el Perú pueda clasificar. ¿Dónde quedaron el mérito y la técnica?

Hace más de una década, Ramonet (2011) preguntaba qué es la noticia atendiendo al público consumidor de información, y los supuestos profesionales le contestaron de la siguiente manera: una buena noticia es aquella que genera interés; es decir, estamos perdiendo nuestro objetivo. Asumiendo la dolorosa realidad, el comunicador español afirmaba en primer lugar que el periodismo se ha sometido a la dictadura de la urgencia, donde la rapidez destrona al correcto proceso y, por lo tanto, la verdad sale perdiendo; en segundo lugar, deploraba la propagación de falsedades y semiverdades en los medios dominantes.

En estas últimas décadas se disfraza lo inmoral como informal, gracioso y novedoso. A pesar de que hay legislación, de la existencia de códigos de ética y de la capacidad de distinguir comúnmente lo que le hace bien a la sociedad de lo que le hace daño, tanto los dueños de las entidades informativas y de entretenimiento como sus consumidores no se inmutan, no reflexionan sobre la función, rol o papeles de los productos audiovisuales y escritos que entregan o reciben. Hay un desconocimiento sobre los derechos de las audiencias y somos testigos de sus graves consecuencias: cada vez crecen más los índices de criminalidad en todos los ámbitos y sectores, a lo que se suma la incapacidad de las personas para organizarse y solucionar los problemas sociales que los agobian. ¿Quién o quiénes son los responsables?

Definitivamente, Internet nos pone en otro escenario, pero debemos entender al periodismo como una profesión, con toda su ciencia y teoría de 
la comunicación, con todas sus técnicas y parámetros; de lo contrario, lo desnaturalizamos. Que la «red de redes» nos haya convertido en «dateros» o nos permita estar en el centro de algunos acontecimientos no nos hace periodistas, porque el verdadero periodista no es un transmisor o difusor, para eso no se estudia.

Estamos hablando de los periodistas que saben investigar y generan todo un proceso como producto de sus conocimientos y estrategias, saben qué es un reportaje y cuándo escribir una crónica, son dialogadores que sin gritar ni generar polémica logran la verdad en una entrevista, predicen los efectos de los mensajes y por eso los construyen con ética. Un buen ejemplo para entender lo grave que es dejar al periodismo en manos de personas no preparadas e inescrupulosas es la siguiente reflexión: que alguien conozca los beneficios de algunas plantas para la salud y que prepare infusiones eficaces no lo convierte en médico. Con las justas puede llegar a curandero, pero jamás será médico a menos que estudie, se gradúe, cumpla su residencia y se colegie.

La segunda falencia de Ibarra es el desconocimiento de las normas legales. Vamos a llamarle incompetencia, porque tendría otro nombr el incumplimiento deliberado de la Ley $\mathrm{N}^{\circ} 28278$. Empecemos con su artículo II: Principios para la prestación de los servicios de radiodifusión:

a) La defensa de la persona humana y el respeto a su dignidad.

b) La libertad de expresión, de pensamiento y de opinión.

c) El respeto al pluralismo informativo, político, religioso, social y cultural.

d) La defensa del orden jurídico democrático, de los derechos humanos fundamentales y de las libertades consagradas en los tratados internacionales y en la Constitución Política.

e) La libertad de información veraz e imparcial.

f) El fomento de la educación, cultura y moral de la Nación.

g) La protección y formación integral de los niños y adolescentes, así como el respeto de la institución familiar.

h) La promoción de los valores y la identidad nacional.

i) La responsabilidad social de los medios de comunicación. 
j) El respeto al Código de Normas Éticas.

k) El respeto al honor, la buena reputación y la intimidad personal y familiar.

1) El respeto al derecho de rectificación.

Vamos a trabajar los siguientes incisos: e), f), g), h), i) y j). El cumplimiento de la ley es esencial para generar una sana convivencia entre todos los ciudadanos de un país. Sin respeto a las leyes estaríamos bajo el imperio del más fuerte y nuestra ciudad se convertiría en una jungla de cemento. El inciso e) se refiere al trabajo profesional de un periodista: si el medio de comunicación ofrece entregarnos un producto informativo, no es solamente un dato ni una opinión, debe ser un material muy bien trabajado, con las teorías, con las técnicas, con los géneros correspondientes. El consumidor de noticias requiere recibir un producto de calidad, que le permita tomar buenas decisiones para cambiar su realidad y generar el bienestar colectivo.

Con los comentarios del señor Ibarra no se puede fomentar información, educación o socialización porque basar una clasificación deportiva en el fracaso de los contrincantes y no en los méritos de los jugadores es desmoralizante. ¿Cuál es la lectura que recoge el imaginario colectivo?: «que le vaya mal al otro para que me vaya bien a mí».

Mientras que los padres en casa trabajan para que sus hijos se formen con valores, se respeten y respeten a los demás, los llamados medios democratizadores tradicionales entregan a los niños, a los jóvenes y al Perú entero productos conocidos como «telebasura» e «infobasura» (Aparici y García, 2017): «(...) no es la publicidad, no es la información empresarial económica o política, tampoco son los sitios dedicados al entretenimiento...» (p. 34). Lamentablemente, estos productos ocupan la mayor parte de la programación audiovisual o del espacio en los periódicos, y lo mismo se está detectando en el ciberespacio.

También se debe tomar en cuenta el artículo $40^{\circ}$ de la Ley $\mathrm{N}^{\circ} 28278$, que a la letra dice: «La programación que se transmita en el horario familiar debe evitar los contenidos violentos, obscenos o de otra índole, que puedan afectar los valores inherentes a la familia, los niños y adolescentes. Este horario es el comprendido entre las 06:00 y 22:00 horas». (La cursiva es nuestra). 


\section{Caso JB en ATV / Programa supuestamente de entretenimiento}

\section{Ficha técnica}

Medio de comunicación: Grupo ATV

Propiedad de Albavisión y canal principal del Grupo ATV

Operado por Andina de Radiodifusión Marcello Cúneo (presidente del directorio) Federico Anchorena (gerente general)

Indicativo de señal ATV en Lima: OAY-4Z (analógica), 1867(TDT)

Programa: JB en ATV (8:00 p.m.)

Secuencia: Comicidad en sketch

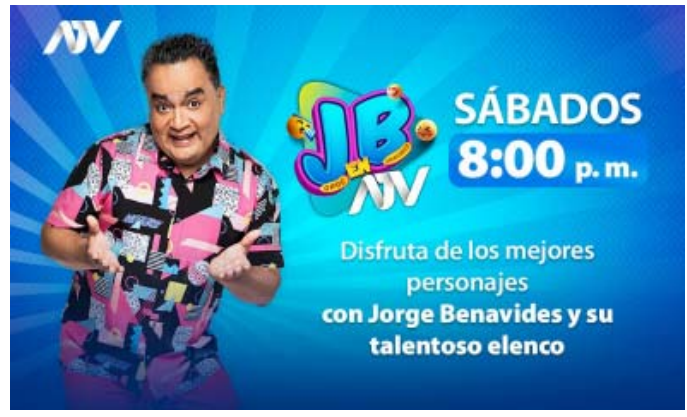

Personajes recreados por Jorge Benavides para analizar

a) La tía Gloria

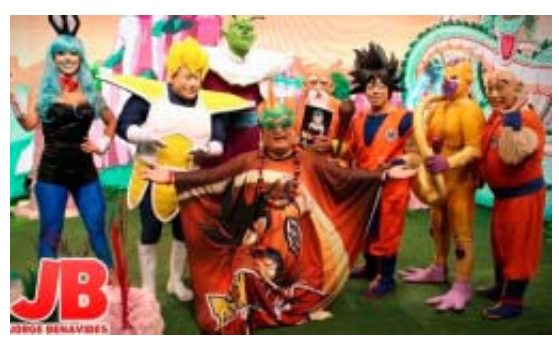

c) Mascaly

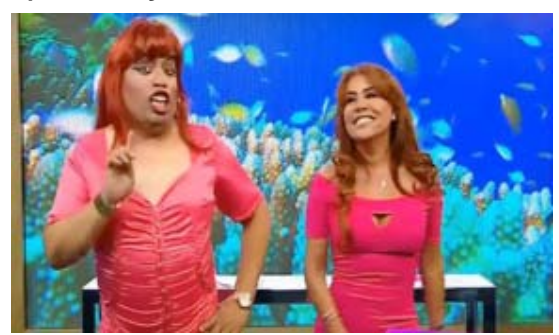

b) El niño Arturito

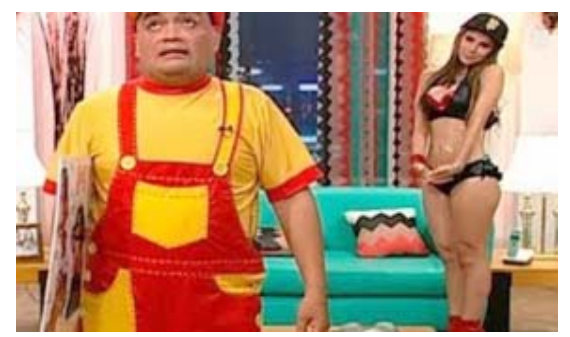

d) Richi

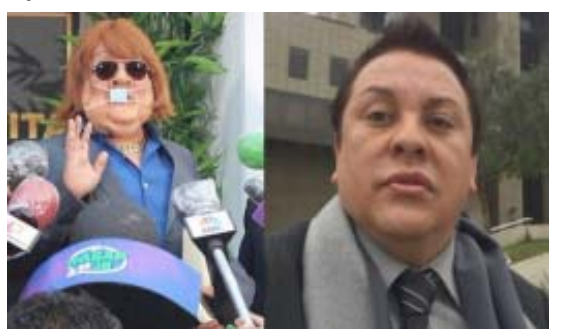




\section{Tabla de observación}

\begin{tabular}{|c|c|c|c|c|}
\hline $\begin{array}{c}\text { Ley N }{ }^{\circ} 28278 \\
\text { Ley de Radio y TV - Art. } 2\end{array}$ & $\begin{array}{l}\text { Personaje } \\
\text { tía Gloría }\end{array}$ & $\begin{array}{l}\text { Personaje } \\
\text { niño Arturito }\end{array}$ & $\begin{array}{l}\text { Personaje } \\
\text { Mascaly }\end{array}$ & $\begin{array}{l}\text { Personaje } \\
\text { Richi }\end{array}$ \\
\hline $\begin{array}{l}\text { a) La defensa de la } \\
\text { persona humana y el } \\
\text { respeto a su dignidad. }\end{array}$ & $\begin{array}{l}\text { Es prepotente y se } \\
\text { burla de su elenco, } \\
\text { mofándose de sus } \\
\text { asuntos personales. }\end{array}$ & $\begin{array}{l}\text { A pesar de } \\
\text { caricaturizar a un niño, } \\
\text { es morboso y actúa } \\
\text { con mujeres } \\
\text { voluptuosas.El } \\
\text { personaje es } \\
\text { perturbador. }\end{array}$ & $\begin{array}{l}\text { Es prepotente y } \\
\text { maltratadora, se burla } \\
\text { de su personal. }\end{array}$ & $\begin{array}{l}\text { Es prepotente } \\
\text { maltratador y corrupto, } \\
\text { además de morboso. } \\
\text { Jorge Benavides hace } \\
\text { escarnio de la vida } \\
\text { sexual de Richard } \\
\text { Cisneros. }\end{array}$ \\
\hline
\end{tabular}

b) La libertad de
expresión, de pensamiento
y de opinión.

c) El respeto al pluralismo informativo, político, religioso, social y cultural.

d) La defensa del orden jurídico democrático, de los derechos humanos fundamentales y de las libertades consagradas en los tratados internacionales y en la Constitución Política.

e) La libertad de información veraz e imparcial.

f) El fomento de la educación, cultura y moral de la nación.

\section{g) La protección y formación integral de los niños y adolescentes, así como el respeto de la institución familiar.}

h) La promoción de los valores y la identidad nacional.

\author{
Impone sus \\ para que piensen \\ como ella. \\ Apoya a su candidata \\ política (Keiko \\ Fujimori). \\ Transgrede las \\ normas, impone sus \\ reglas, todo gira \\ alrededor de ella y le \\ gusta humillar.
}

El lenguaje que usa es Impone sus

pensamientos e intimida de doble sentido.

\section{Da mensajes a favor} del grupo político de su pesar de tener procesos expresidente Vizcarra preferencia.

$$
\text { judiciales. }
$$
y de sus preferencias.

Transgrede las normas Transgrede las normas, Transgrede las y buenas costumbres, impone sus reglas, todo normas, impone sus sexualiza a su gira alrededor de ella y reglas, todo gira personaje, a pesar de le gusta humillar. alrededor de él, le ser visto por niños. gusta humillar y minimiza los actos de corrupción.

Supuestamente es un programa cómico.

Supuestamente es un programa cómico.

Supuestamente es un programa cómico.

Supuestamente es un programa cómico.

Enaltece lo negativo. No fomenta la educación, ni la moral de la nación.

Enaltece lo negativo. No fomenta la

Enaltece lo negativo No fomenta la

Enaltece lo negativo. educación, ni la moral educación, ni la moral educación, ni la moral de la nación. de la nación. de la nación.

A pesar de que está

A pesar de que está

A pesar de que está

A pesar de que está destinado para niños y destinado para niños y destinado para niños para la familia, usa un para la familia, usa un y para la familia, usa lenguaje vulgar y lenguaje vulgar y morboso. morboso. un lenguaje vulgar y morboso. destinado para niños y para la familia, usa un lenguaje vulgar y morboso.

\section{Enaltece los} antivalores, utiliza un Enaltece los Enaltece los antivalores, utiliza un antivalores, utiliza un lenguaje sexualizado y sexista. lenguaje lenguaje sexualizado y sexista.
Enaltece los antivalores, utiliza un lenguaje sexualizado y sexista. 


\begin{tabular}{|c|c|c|c|c|}
\hline $\begin{array}{c}\text { Ley } N^{\circ} 28278 \\
\text { Ley de Radio y TV - Art. } 2\end{array}$ & $\begin{array}{l}\text { Personaje } \\
\text { tía Gloría }\end{array}$ & $\begin{array}{l}\text { Personaje } \\
\text { niño Arturito }\end{array}$ & $\begin{array}{l}\text { Personaje } \\
\text { Mascaly }\end{array}$ & $\begin{array}{l}\text { Personaje } \\
\text { Richi }\end{array}$ \\
\hline $\begin{array}{l}\text { i) La responsabilidad social } \\
\text { de los medios de } \\
\text { comunicación. }\end{array}$ & $\begin{array}{l}\text { ATV Canal } 9 \\
\text { promociona este } \\
\text { programa como estelar } \\
\text { e infringe totalmente la } \\
\text { Ley } N^{\circ} 28278 \text {. }\end{array}$ & $\begin{array}{l}\text { ATV Canal } 9 \\
\text { promociona este } \\
\text { programa como estelar } \\
\text { e infringe totalmente la } \\
\text { Ley } N^{\circ} 28278 \text {. }\end{array}$ & $\begin{array}{l}\text { ATV Canal } 9 \\
\text { promociona este } \\
\text { programa como estelar } \\
\text { e infringe totalmente la } \\
\text { Ley } N^{\circ} 28278 \text {. }\end{array}$ & $\begin{array}{l}\text { ATV Canal } 9 \\
\text { promociona este } \\
\text { programa como estelar } \\
\text { e infringe totalmente la } \\
\text { Ley } N^{\circ} 28278 \text {. }\end{array}$ \\
\hline $\begin{array}{l}\text { j) El respeto al Código de } \\
\text { Normas Éticas. }\end{array}$ & $\begin{array}{l}\text { No se respetan las } \\
\text { normas éticas. }\end{array}$ & $\begin{array}{l}\text { No se respetan las } \\
\text { normas éticas. }\end{array}$ & $\begin{array}{l}\text { No se respetan las } \\
\text { normas éticas. }\end{array}$ & $\begin{array}{l}\text { No se respetan las } \\
\text { normas éticas. }\end{array}$ \\
\hline $\begin{array}{l}\text { k) El respeto al honor, la } \\
\text { buena reputación y la } \\
\text { intimidad personal y } \\
\text { familiar. }\end{array}$ & $\begin{array}{l}\text { Se burla de las } \\
\text { personas de su elenco, } \\
\text { de su vida privada y } \\
\text { sexual. }\end{array}$ & $\begin{array}{l}\text { Las invitadas son } \\
\text { exhibidas como objetos } \\
\text { sexuales y hace morbo } \\
\text { de su vida íntima. }\end{array}$ & $\begin{array}{l}\text { Se burla de las } \\
\text { personas de su elenco, } \\
\text { de su vida privada y } \\
\text { sexual. }\end{array}$ & $\begin{array}{l}\text { Se burla de las } \\
\text { personas de su elenco, } \\
\text { de su vida privada y } \\
\text { sexual. }\end{array}$ \\
\hline $\begin{array}{l}\text { l) El respeto al derecho de } \\
\text { rectificación }\end{array}$ & $\begin{array}{l}\text { La señora Gloria Helfer } \\
\text { no se pronuncia. }\end{array}$ & $\begin{array}{l}\text { Es un personaje de } \\
\text { ficción, muy } \\
\text { perturbador. }\end{array}$ & $\begin{array}{l}\text { Tiene el consentimiento } \\
\text { de la señora Magaly } \\
\text { Medina. }\end{array}$ & $\begin{array}{l}\text { El señor Richard } \\
\text { Cisneros ha pedido } \\
\text { que no lo imite. }\end{array}$ \\
\hline $\begin{array}{l}\text { Artículo } 40^{\circ} \text { : Horario } \\
\text { familiar:La programación } \\
\text { que se transmita en el } \\
\text { horario familiar debe evitar } \\
\text { los contenidos violentos, } \\
\text { obscenos o de otra índole, } \\
\text { que puedan afectar los } \\
\text { valores inherentes a la } \\
\text { familia, los niños y } \\
\text { adolescentes. Este horario } \\
\text { es el comprendido entre } \\
\text { las } 06: 00 \text { y } 22: 00 \text { horas. }\end{array}$ & $\begin{array}{l}\text { El programa se emite } \\
\text { los sábados a las 8:00 } \\
\text { p.m. } \\
\text { El personaje es } \\
\text { violento, usa lenguaje } \\
\text { en doble sentido y le } \\
\text { gusta maltratar a sus } \\
\text { coprotagonistas. Y lo } \\
\text { más perturbador es } \\
\text { que su personaje } \\
\text { dirige el casting para } \\
\text { programas infantiles. }\end{array}$ & $\begin{array}{l}\text { El programa se emite } \\
\text { los sábados a las 8:00 } \\
\text { p.m. } \\
\text { A pesar de caracterizar } \\
\text { a un niño, se presenta } \\
\text { con mujeres de la } \\
\text { farándula y actúa de } \\
\text { manera morbosa, } \\
\text { haciendo escarnio de } \\
\text { los asuntos de su vida } \\
\text { personal. Es un sketch } \\
\text { demasiado } \\
\text { sexualizado. }\end{array}$ & $\begin{array}{l}\text { El personaje utiliza un } \\
\text { lenguaje vulgar y en } \\
\text { doble sentido, es } \\
\text { prepotente y ordinario. }\end{array}$ & $\begin{array}{l}\text { Vulgariza la identidad } \\
\text { sexual del personaje. } \\
\text { Hace escarnio de la } \\
\text { vida privada e íntima } \\
\text { del personaje imitado. }\end{array}$ \\
\hline
\end{tabular}

Fuente: Elaboración propia de acuerdo a las fichas de observación. 


\section{Resultados}

Como actor y productor Jorge Benavides se dedica a parodiar, no existe un solo personaje de su inventiva o creatividad, las situaciones y circunstancias también son parodiadas sobre hechos reales, gente de la farándula o de la política.

Existe una incidencia significativa entre los cuatro personajes analizados; por ejemplo, todos son prepotentes, sin ningún tipo de valores, transgresores, les gusta tener el poder y humillar.

El personaje perturbador para el público infantil es «Arturito». En esta secuencia se caracteriza a un niño que está enamorado de la invitada al programa, pero para su presunta edad está muy sexualizado y hace preguntas y comentarios en doble sentido.

A pesar de que se emiten dentro del horario de protección al menor, los sketchs utilizan un lenguaje vulgar y en doble sentido. La mayoría de los chistes trata sobre sexo o la sexualidad de algunos de los personajes o de los integrantes del elenco.

Los resultados demostraron que las mujeres que trabajan en el programa están estereotipadas, participan con poca ropa o muy ajustada, enfatizando una silueta voluptuosa.

El centro de todo el programa es Jorge Benavides, nadie más se puede lucir como actor, como cómico o tener una secuencia; especialmente las mujeres de su elenco que solamente están para «jalar» visualmente.

Al hacer seguimiento de sus personajes, se detectó la incidencia en reiteradas ocasiones de invitar al programa a los procesados hermanos Fujimori, que aparecen sobre todo en época de elecciones o cuando tienen problemas judiciales, para «suavizar» su imagen. 


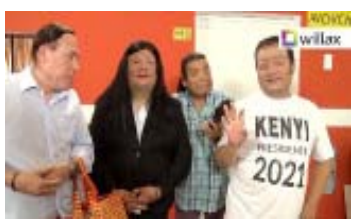

Fecha: $30 / 4 / 21$

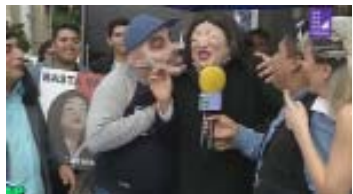

Fecha: $2 / 12 / 20$

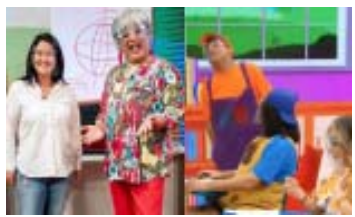

Fecha: $20 / 3 / 21$

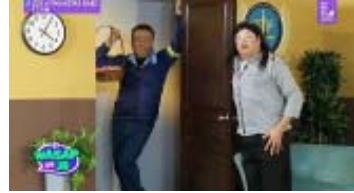

Fecha: $20 / 10 / 18$

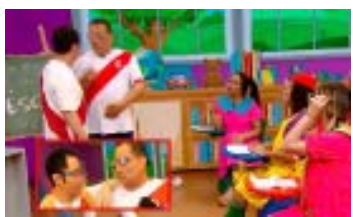

Fecha: $26 / 5 / 21$

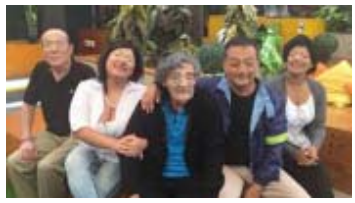

Fecha: 20/3/18

Fuente: Fotografías de la página del programa JB en ATV. https://www.atv.pe/programa/jb-en-atv

También tenemos que indicar que por mandato judicial no se emiten la secuencia ni el programa La Paisana Jacinta, basados en el racismo, la marginación y el desprecio por el otro. La ley lo contempla, la Responsabilidad Social Empresarial (RSE) también y estaba en manos del Ministerio de Transportes y Comunicaciones (MTC), en manos de la Sociedad Nacional de Radio y Televisión (SNRTV), pero fue el Poder Judicial el que tuvo que encargarse finalmente de hacer cumplir la ley, porque hasta el momento la autorregulación, para algunos medios de comunicación, al parecer no existe.

$$
\text { TELEVISIÓN (if) (4) () in (6) }
$$

Poder Judicial ordena que "La Paisana Jacinta" sea retirada de YouTube, Facebook y más redes sociales

Una nueva resolución prolibe a Benavides a crear nuevo contenido del polémico personaje en sus redes sociales privadas y püblicas.

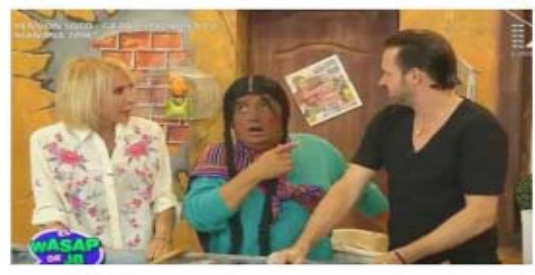

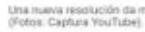

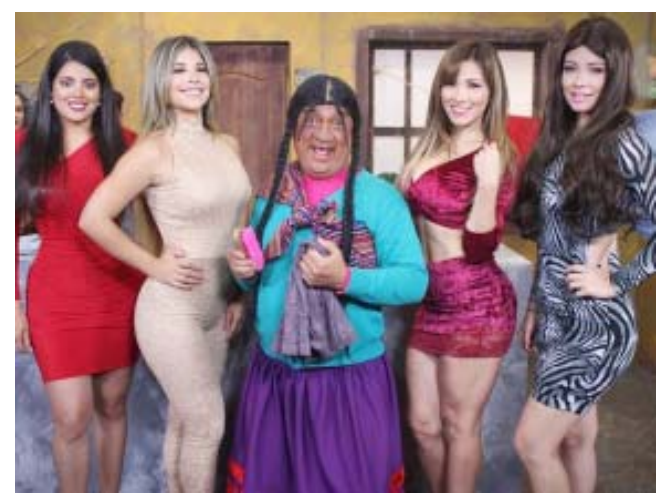

Fuente: Diario El Comercio, online (17/12/20). 
La existencia de La Paisana Jacinta creaba un halo de permisibilidad al referirse de forma peyorativa a las personas de las zonas andinas, a quienes conocemos como «paisanas». Incluso se permitía en varias de sus secuencias poner adjetivos ofensivos a la protagonista o burlarse de su forma de hablar. Bruce (2007) considera que el racismo es una práctica tóxica en el Perú, arraigado en las interacciones sociales con mucha más fuerza que en otros países con instituciones que regulan dichas interacciones.

Es tarea de los medios de comunicación socializar, no fomentar el racismo ni construir climas de permisibilidad. En la información y en el entretenimiento debe existir coherencia, pues ambos productos tienen un deber transversal: la socialización; de lo contrario, se gesta una sociedad hipócrita donde en las noticias se critica y hasta se pide sanción para los actos racistas, pero en la sección o programa de entretenimiento se aplaude la marginación y la prepotencia, entre otros elementos que generan conflictos sociales.

\section{La falta de identidad}

Este es uno de los factores por los cuales tenemos problemas y hasta una de las peores crisis en la industria de la comunicación, información y entretenimiento. Personas ajenas a la formación universitaria en ciencias de la comunicación han distorsionado la noble tarea de defender la verdad y de fomentar el sano esparcimiento. Todo este caos es propiciado por la falta de identidad.

Pero cómo construir una identidad, si hasta existe legislación que maltrata a la profesión en nuestro país, como la Ley $\mathrm{N}^{\circ} 26937$ que desnaturaliza la existencia del Colegio de Periodistas, al contemplar el libre ejercicio de la actividad y la no obligatoriedad de la colegiación. Esta ley generó la peligrosa pérdida de los ideales de los hombres de prensa. A partir de su promulgación, no se registra ni se hace seguimiento a la ética de los que sin estudiar y sin colegiatura ejercen el periodismo. Es importante deslindar, revisar y adecuar a la realidad esta ley, porque un asunto es el derecho del individuo a opinar y expresarse, consagrado en la mayoría de las constituciones del mundo; y otro asunto -también muy delicado- es informar. Queda en claro que informar es un proceso que requiere un conocimiento 
multidisciplinario; por tanto, no se pueden menospreciar las funciones y labores de los periodistas. El ejercicio del periodismo requiere la comprensión perfecta de las ciencias de la comunicación y de todas sus teorías. El conocimiento y uso responsable de las herramientas comunicativas exige el componente ético, el compromiso con la verdad y con el bienestar social.

Los comunicadores son profesionales de la verdad. En cualquiera de las especialidades se reconoce el valor e importancia de este insumo para la democracia; lamentablemente se usa el relativismo pragmático para desvirtuar la función social de los profesionales de la información, convirtiéndolos en divulgadores mas no en procesadores de noticias, dejando a su audiencia sin capacidad de respuesta. Por ello debemos tener en cuenta lo que Blanco (2018) afirmaba sobre la percepción y la capacidad semiotizante del ser humano frente a la definición vulgar de objeto. La subjetividad juega un papel preponderante; entonces, al mundo no lo vemos como es. Y lo que no vemos no es.

La semiótica marca la ruta para entender la producción social de las empresas de comunicación, sus productos nos alejan de la realidad, tal vez para no conocer con objetividad lo que está pasando en el mundo. Al impedirnos percibir lo que es, pensamos que no existe; y al hacernos percibir lo que no es, pensamos que existe. Como, por ejemplo, calificar de programa periodístico a una secuencia de chismes de la farándula, o de periodismo deportivo a los chismes sobre los atuendos, peinados y novias de los deportistas, cuando en realidad no hay un mínimo tratamiento para que a ese producto informativo se le considere de calidad y cumpla su función social.

Es vital el argumento sobre percepción y es por ello que no cualquiera puede ser periodista, porque este ha de ser un excelente comunicador con conocimientos de semiótica y de otras materias igual de importantes, que le permitan ver de manera objetiva la realidad y construir, también de manera objetiva, la noticia o el producto comunicativo en los distintos formatos y plataformas.

Entonces, para construir una identidad, hay que definir a los actores en la industria de la comunicación, información y entretenimiento: el empresario, especialista en administración, ingeniería industrial y afines; el periodista, al 
que se le debe devolver su estatus de profesional, con leyes que respalden su importante labor a favor de la democracia y socialización; finalmente, el gremio propiamente dicho, que requiere ser potenciado con un colegio de periodistas capaz de dignificar la labor de cada uno de sus miembros y de sancionar de aquellos que osen utilizar los conocimientos y técnicas en contra de la profesión y de la sociedad.

Este no es solamente un problema exclusivo del Perú, es un problema mundial, pero será materia para otra investigación.

\section{La ética: al rescate de los medios de comunicación al enaltecer su papel de socialización}

Cuarto poder. No se le otorgó en vano esta nomenclatura al periodismo, al querer graficar su importancia en la socialización. También se calificó a los medios de comunicación como elementos democratizadores, porque informan, educan, entretienen, motivan, integran, generan avance cultural y debate para el consenso; todo ello dentro del marco de la ética. La formación de los comunicadores debe incluir la ética de manera transversal, para cultivar al ser humano. Si la persona busca el bien para sí y para los demás, entonces habremos evolucionado.

Podemos tener la última tecnología, podemos usar estrategias de novísima generación, pero sin ética de nada van a servir, inclinarán las balanzas a ciertos extremos y tendremos periodistas que se autocensuran por conveniencia, programas televisivos, periódicos y radios «basura».

La existencia y progreso de la humanidad dependen de la calidad de sus interacciones, de una asertiva simbiosis social; eso es innegable. Somos seres sociables por naturaleza. Pero qué pasa cuando muere el espíritu y deviene el vacío existencial. Tomemos el ejemplo que Ayllón (2011) recoge de la experiencia de un mítico cantante: antes de suicidarse Kurt Cobain declaraba que no deseaba caer en la adicción porque era consciente de su autodestrucción, pero el poder de adhesión de la heroína, de esa sustancia química que le hacía perder la voluntad sobre su biología, lo convertía en un incoherente, porque terminaba vencido diariamente en la lucha entre lo que debía hacer frente a lo que lo mataría. 
En su programa La función de la palabra, que se transmitía por el canal del Estado, Marco Aurelio Denegri (2010) aseveró que la «televisión basura» era tan adictiva como el alcohol y la pasta básica de cocaína. Según el reconocido intelectual, la basura produce adicción, su difusión diaria genera acostumbramiento. Para demostrar que la hediondez y la pestilencia son adictivas se refirió en otro de sus programas a un episodio real en la capital del imperio alemán hacia década de 1870: cuando se recogió la basura la gente protestó en las calles. Su investigación no debe ser pasada por alto, ya que está fundamentada en hechos médicos, como la perversión llamada cacosmia: «la basura que se produce y esparce diariamente en la televisión es peligrosísima ya que origina una adición violenta y tenaz, los televidentes se acostumbran a la cochinada químicamente pura y a la vulgaridad más atroz» (Denegri, 2011).

Es el momento histórico en el que toca mirarnos como humanidad y ver cómo hemos evolucionado; no nuestra ciencia, no nuestra tecnología, sino el hombre. Cultivar al ser humano, enaltecer su espíritu y darle calidad de vida: esos deben ser los objetivos, las metas. La evolución parte de avanzar como grupo, asumiendo nuestras responsabilidades en comunidad, haciendo el bien común. Todos debemos tener las ideas claras, porque al estilo Kurt Cobain algunos difunden y confunden el placer con la felicidad y terminan químicamente devastados. El individualismo egoísta y la carencia de virtudes y valores fragmentan la identidad humana. En lugar de luchar por la sana convivencia, procurando un futuro mejor, se enaltece todo lo negativo. ¿Hacia dónde vamos?

Si deseamos llegar a buen puerto es importante volver nuestra mirada a la ética, como lo argumenta Aguirre (2016), quien nos recuerda la trascendencia de la función social de las organizaciones de comunicación a través de tres importantes argumentos: la ética aplicada a los contenidos, la ética profesional y la ética de la empresa.

No hay que tener miedo, hay que preferir el bien. No hay que tener vergüenza, hay que hacer las cosas bien. Leuridan (2019) nos habla de una invitación al cambio, proponiendo la ética como el camino para encontrar la realización del ser humano, siendo el Amor ese camino. Cuando hablamos de evolucionar como humanidad, lo que nos dignifica y hace progresar son nuestros valores, nuestras virtudes, la moral y la ética. 


\section{Conclusiones}

Los empresarios y los profesionales de la comunicación deben asumir un compromiso ético en la administración de sus herramientas para devolver sus auténticas funciones a todo este sector.

La socialización es un deber fundamental de los profesionales y de las empresas de comunicación y solamente se logrará dentro del marco ético.

A pesar de los esfuerzos y disertaciones sobre la crisis en las empresas de comunicaciones y entre los profesionales, los empresarios de dicho rubro no se pronuncian ni menos toman medidas frente a esta situación.

Los comunicadores están golpeados por la falta de identidad y por la existencia de leyes que desnaturalizan a su gremio.

Otro grupo de comunicadores, especialmente los empíricos, actúa según las órdenes de quien los contrata.

Analizar lo que dice un conductor de la sección deportiva o cómo se gesta el humor para toda la familia en un canal de televisión grafica la cruda verdad sobre la moral de la sociedad y el comportamiento ético de dichos profesionales. No hay calidad en esos productos porque no existen los controles correspondientes.

Se debe trabajar en la identidad del comunicador y en eliminar todas las leyes que vayan contra la noble labor de defender la verdad.

La formación del periodista debe ser sólida en valores éticos, previo rescate y recuperación de su identidad.

Para lograr que los medios de comunicación cumplan su función es importante volver a fomentar los valores, las virtudes y la moral en la formación humana.

Se debe educar a la población en todos los niveles para que pueda exigir el cumplimiento de la ley, en este caso la Ley $\mathrm{N}^{\circ} 28278$, y poder consumir productos de calidad. 


\section{Referencias}

Aguirre, M. (2016). Ética de los medios de comunicación. Herder Editorial.

Aparici, R. y García, D. (2017). Comunicar y educar en el mundo que viene. Editorial Gedisa.

Arboccó, M. y O'Brien, J. (2012). Impacto de la 'televisión basura' en la mente y la conducta de niños y adolescentes. Avances en Psicología, 20(2), 43-57. https://revistas.unife.edu.pe/index.php/avancesenpsicologia/article/view/ $318 / 236$

Ayllón, J. (2011). Aristóteles Ética. Segunda edición. Ediciones Palabra.

Benavides, J. (2021). JB en ATV [Programa cómico]. https://www.atv.pe/programa/jb-en-atv

Blanco, D. (2018). Semiótica del texto fílmico. Fondo Editorial de la Universidad de Lima.

Bruce, J. (2007). Nos habíamos choleado tanto. Fondo Editorial de la Universidad de San Martín de Porres.

Denegri, M. A. (2010). «La adicción a la basura televisiva» [video]. https://youtu.be/tTFYi-yXqxo

Denegri, M. A. (2011). «La cacosmia y el enmierdamiento televisivo» [video]. https://youtu.be/UF5UNaVkHDc

Durkheim, E. (2011 [1883]). El rol de los grandes hombres en la historia. Escritos políticos. Gedisa.

El Comercio. (2020). Poder Judicial ordena que «La Paisana Jacinta» sea retirada de You Tube, Facebook y demás redes sociales. https://elcomercio.pe/tvmas/television/poder-judicial-ordena-que-la-paisana-jacintasea-retirada-de-youtube-facebook-y-mas-redes-sociales-jorge-benavides-nndc-noticia/

Latina Televisión. (2021, 10 de septiembre). «Checho» Ibarra es sorprendido por su esposa en el bloque deportivo de 90 Matinal. https://www.latina.pe/deportes/futbol-peruano/checho-ibarra-es-sorprendido-porsu-esposa-en-el-bloque-deportivo-de-90-matinal

Leuridan, J. (2019). El sentido de las dimensiones éticas de la vida. Fondo Editorial de la USMP.

Ley Nº 28278, Ley de Radio y Televisión. (2004). Congreso de la República del Perú. https://cdn.www.gob.pe/ uploads/document/file/19067/1_0_3537.pdf

Mac Bride, S. (1980). Un solo mundo, voces múltiples. Comunicación e información en nuestro tiempo. México: Fondo de Cultura Económica.

Ramonet, I. (2011). La explosión del periodismo, Internet pone en jaque a los medios tradicionales. Le Monde Diplomatique.

Vygotsky, L. S. (1981). Pensamiento y lenguaje. La Pléyade. 